\title{
A comparative study of self stigma between HIVIAIDS and schizophrenia patients
}

\author{
Taiwo Olamide Oduguwa, Olusegun Oladimeji Akinwotu, Adefemi Adegoke Adeoye \\ Federal Neuropsychiatric Hospital, Harvey Road, Yaba Lagos State Nigeria
}

\begin{abstract}
Objective: To compare and assess the extent, domains and socio-demographic correlates of self-stigma in schizophrenia and HIV positive patients. Method: Schizophrenia (study group) out patients $(n=91)$ and HIV positive (comparison group) out-patients $(n=91)$ from 2 hospitals in Lagos, were administered a socio-demographic questionnaire to evaluate various socio-demographic variables, and a modified version of Internalized Stigma of Mental Illness Scale (ISMI), as a measure of their self-stigma. Analysis was done using the statistical package for social sciences.Results: $A$ total of $43(47.3 \%)$ schizophrenia and 35 (38.5\%) HIV positive patients were classified as having "moderate-severe" self-stigma. Majority of the respondents in both groups had been aware of their diagnosis between 1-5 years. The socio-demographic correlates of high self-stigma in the schizophrenia group were low level of education and unemployment; while for the HIV positive group, it was being single. The schizophrenia patients had a significantly higher level of self-stigma over all and also same on the alienation, discrimination and stereotype experience sub-scales than the HIV group. Conclusion: Self-stigma is more evident in schizophrenia patients than HIV positive patients, which are both debilitating and highly stigmatized illnesses. Urgent attention thus needs to be put in place, by creating more support and advocacy groups in the country to reduce the level of stigma in them, thus improving their overall quality of life.
\end{abstract}

Keywords: Self-stigma; HIV; Schizophrenia

Received date: $2-12-2013$

Accepted date: $30-01-2014$

doi: http://dx.doi.org/10.4172/Psychiatry.1000109

\section{Introduction}

Stigma is a common human reaction to a disease. ${ }^{1}$ It can be conceptualized in different ways. Individuals suffer from self-stigma when they internalize negative perceptions regarding themselves, as against perceived stigma where they suffer from other people's prejudicial attitudes and discriminatory behavior., ${ }^{2,3}$

The process of internalizing stigma is said to be complex, however, internal stigma has been linked with external stigma. 3 This is due to the fact that fear of judgment or discrimination from others can profoundly influence the way people living with chronic diseases view themselves and cope with their disease state. Whichever kind of stigma it is, can lead to impoverishment, social marginalization and low quality of life. ${ }^{3}$

In comparison with other disorders, many patients with mental illness experience stigma and this has been termed the "ultimate" stigma. ${ }^{3}$ Historically, even though mental illness stigma has existed long before psychiatry, stigma has still not gone away despite scientific advances. ${ }^{4,5}$ Schizophrenia is typically equated with lunacy, heritability, aggression, contagion, unpredictability and untreatability. ${ }^{6}$ When individuals face the onset of mental illness like schizophrenia, they develop stereotypes, which become relevant to the self. ${ }^{6}$

Correspondence

Taiwo 0 Oduguwa

Federal Neuropsychiatric Hospital,

Harvey Road,

Yaba Lagos State

Nigeria

E-mail: odug2@yahoo.co.uk
Such stereotypes include that people with mental illness are dangerous, incompetent and to blame for their illness.7 According to the modified labeling theory perspective, this belief stems from the fact that individuals with mental illness had internalized cultural stereotypes about mental illness, prior to being labeled as mentally ill. ${ }^{8}$ Most individuals with diagnosis of schizophrenia will be confronted with some form of stigmatization. ${ }^{9}$ They may be devalued and discriminated against because of their mental illness. ${ }^{10}$ Concerns about mental illness stigma has increased over the past several decades, thus setting up several psychiatric organizations and mounting "anti-stigma campaign". ${ }^{11}$

It is however uncertain the effect of these campaigns on public attitudes on experiences of people with mental illness. ${ }^{12}$

Stigma is not unique to mental illness. It has been seen throughout history in relation to other diseases including tuberculosis, human immunodeficiency virus (HIV) infection, syphilis and leprosy. ${ }^{13}$ HIV/AIDS is yet another highly stigmatizing disease. HIV has been stigmatized because it can be fatal and therefore causes fear, it is often associated with behavior that is already stigmatized; such as sex work. Also infection is seen as the result of "choices" made (e.g., "choices" to have unprotected sex or to share needles to inject drugs); and this is seen as punishment for deviant behavior. ${ }^{14}$

Although stigma in people living with HIV and schizophrenia have different causations and underlying stereotypes, the consequences are similar. It affects the quality of life of individuals as well as the effectiveness of many public health programs. ${ }^{15}$ There is a dearth of information on the comparison of stigma in schizophrenia 
and HIV positive patients. One of the few studies was carried out by. ${ }^{16}$ It showed that discriminatory attitudes towards the two groups were prevalent, but stronger towards people living with HIV/AIDS than people living with mental illness.

There have been varying results in the literature on the prevalence of self-stigma in people living with HIV and AIDS (PLWHA) and in people with mental disorders. A study done on AIDS (PLWHA), found that $28 \%$ of respondents admitted to more than one item addressing internalized stigma on an HIV/AIDS stigma instrument-PLWA (HASI-P). ${ }^{17}$ In a study carried out in Europe $41.7 \%$ of patients with schizophrenia, psychosis or affective disorder had been reported to have moderate to high levels of self-stigma. ${ }^{18}$

A prevalence of $40 \%$ of patients with mental illness in Iran have moderate to severe self-stigma. ${ }^{19}$ However a study on self-stigma in South west Nigeria found that $21.6 \%$ of respondents had high self-stigma. ${ }^{20}$

Although there have been studies carried out on stigma in the mentally ill generally in our environment, there have been no studies carried out on stigma in patients with a particular diagnosis such as patients suffering from schizophrenia. ${ }^{21}$ Also the available studies have been limited to mental illness, without comparing it to any other chronic illness. This study sets out to compare the extent of selfstigma and compare their socio-demographic correlates, in two chronic and highly stigmatizing illnesses; Schizophrenia and HIV/AIDS.

\section{Methods}

The study was conducted in the Federal Neuropsychiatric Hospital Yaba (FNPHY) Lagos and Lagos State University Teaching Hospital (LASUTH). Respondents were recruited from the general out-patient unit and hematology outpatient units respectively of both hospitals. Both hospitals are tertiary health institutions. The former providing mental health services, while the latter provides various kind of health services. Both institutions provide specialist training.

\section{Subjects}

The study consisted of a study group (schizophrenia patients) and a comparative group (HIV positive patients). The study group consisted of 91 , consecutive attendees of the out-patient clinic of FNPHY, who were age 18 years and above.

The inclusion criteria were, giving an informed consent, fulfilling the ICD 10 diagnostic criteria for schizophrenia. Patients also had to have been on antipsychotic medications for at least 6 months.

Those who were too ill to respond to the questionnaire, those having co morbid psychiatric axis 1 diagnosis (ICD 10 multi-axial), or having chronic co morbid conditions were excluded from the study.

A comparison group of HIV positive patients, matched for age and sex were used. Inclusion criteria were, informed consent, respondents being 18 years and above, confirmed diagnosis of HIV infection (using the Western Blot method), respondents had to have been on anti-retroviral medications for at least 6 months. Exclusion criteria were those who were too ill to respond to questions or those with a co morbid medical or psychiatric condition.

The study was carried out between June 2011 and October 2011.

\section{Procedure}

Ethical approval was obtained from the ethical committees of Federal neuropsychiatric hospital, Yaba and Lagos state university teaching hospital, Ikeja. All the participants were duly informed about the study and its purpose. Informed consent was also obtained from them. Information from the respondents was kept confidential.

Twoinstrumentswereusedinthestudywhichwere:asociodemographic questionnaire and the internalized stigma of mental illness (ISMI) scale. ${ }^{22}$ Patients were administered either the English version or the back translated Yoruba version of the instrument. The questionnaires were mostly self- administered. Questionnaires were administered to illiterate respondents.

The socio-demographic data questionnaire was used to address items such as age, gender, educational status, marital status, employment status, educational qualification, occupation, duration of illness etc. Other items included the presence of any other diagnosed chronic illness. The questionnaires were administered to all the respondents that took part in the study.

Self-stigma was measured using a modified version of the Internalized Stigma of Mental Illness (ISMI) scale. ${ }^{22}$ It is a 29 -item scale subdivided into 5 subscales. This is designed to measure the subjective experience of stigma, with 5subscales measuring alienation, Stereotype Endorsement, Perceived discrimination, Social withdrawal and Stigma resistance. Answers to the questions are rated using a 4-point Likert-type agreement scale, (1) being strongly disagree, while (4), strongly agree. The instrument has been found to be psychometrically sound, and has been found to be suitable for our environment. The modified and validated version for our environment consisting of 4 subscales, (excluding stigma resistance) was used. Each subscale has a total of 6 questions each; making a total of 24 questions. ${ }^{23}$ The responses were dichotomized into disagreed $(0)$ or agreed (1). The higher the scores, the higher the self-stigma. On face validity, this instrument is seen to be adequate for the HIV positive respondents.

\section{Measures}

The total mean scores of respondents, on the 4 subscales in each group (Schizophrenia and HIV) were determined. This was used as the cut off point for severity of self-stigma. Those that had scores below the mean for their group were regarded as having no to mild self-stigma. And those that had scores above the mean for their groups were regarded as having moderate to severe levels of self-stigma.

\section{Data analysis}

Analysis was done using the statistical package for social sciences (SPSS)-Version 14.0 (SPSS, Chicago IL, USA). Descriptive and inferential statistics were done. F-test was used to compare 2 independent groups, students T-test was used to compare means of continuous variables. Chi-square was used for comparison of categorical variables. Levels of significance were set at $\mathrm{P}<0.05$.

\section{Results}

\section{Socio-demographic details}

The socio-demographic characteristics of the patients and controls are shown in Tables 1-3.

The total number of males was $48(52.7 \%)$ while the number of females was $43(47.3 \%)$. The mean age of 


\begin{tabular}{|c|c|c|c|}
\hline & & SCHIZOPHERNIA & HIV \\
\hline \multirow[t]{2}{*}{ Age } & Mean & 37.2 & 36.9 \\
\hline & S.D & 7.6 & 7.6 \\
\hline \multirow{7}{*}{ Age Group } & Less than 25 & $4(4.4)$ & $4(4.4)$ \\
\hline & $25-29$ & $12(13.2)$ & $14(15.4)$ \\
\hline & $30-34$ & $21(23.1)$ & $19(20.9)$ \\
\hline & $35-39$ & $17(18.7)$ & $18(19.8)$ \\
\hline & $40-44$ & $13(14.3)$ & $14(15.4)$ \\
\hline & More than 45 & $24(26.4)$ & $22(24.2)$ \\
\hline & TOTAL & $91(100)$ & $91(100)$ \\
\hline \multirow{3}{*}{ Gender } & Male & $48(52.7)$ & $48(52.7)$ \\
\hline & Female & $43(47.3)$ & $43(47.3)$ \\
\hline & TOTAL & $91(100)$ & $91(100)$ \\
\hline \multirow{5}{*}{ Marital Status } & Single & $50(54.9)$ & $14(15.4)$ \\
\hline & Married & $29(31.9)$ & $58(63.7)$ \\
\hline & Divorced & $11(12.1)$ & $14(15.4)$ \\
\hline & Widowed & $1(1.1)$ & $5(5.5)$ \\
\hline & TOTAL & $91(100)$ & $91(100)$ \\
\hline \multirow{5}{*}{ Ethnicity } & Yoruba & $56(61.5)$ & $34(37.4)$ \\
\hline & Ibo & $23(25.3)$ & $33(36.3)$ \\
\hline & Hausa & $0(.0)$ & $3(3.3)$ \\
\hline & Others & $12(13.2)$ & $21(23.1)$ \\
\hline & TOTAL & $91(100)$ & $91(100)$ \\
\hline \multirow{5}{*}{ Religion } & Islam & $13(14.3)$ & $14(15.4)$ \\
\hline & Christianity & $78(85.7)$ & $74(81.3)$ \\
\hline & Traditional & $0(.0)$ & $1(1.1)$ \\
\hline & Others & $0(.0)$ & $2(2.2)$ \\
\hline & TOTAL & $91(100)$ & $91(100)$ \\
\hline \multirow{4}{*}{ Educational Status } & Primary & $5(5.5)$ & $12(13.2)$ \\
\hline & Secondary & $34(37.4)$ & $47(51.6)$ \\
\hline & Tertiary & $52(57.1)$ & $32(35.2)$ \\
\hline & TOTAL & $91(100)$ & $91(100)$ \\
\hline \multirow{3}{*}{ Employment Status } & Employed & $38(41.8)$ & $60(65.9)$ \\
\hline & Unemployed & $53(58.2)$ & $31(34.1)$ \\
\hline & TOTAL & $91(100)$ & $91(100)$ \\
\hline \multirow{5}{*}{ Duration of Illness } & Less than 1 year & $13(14.3)$ & $13(14.3)$ \\
\hline & $1-5$ years & $45(49.5)$ & $75(82.4)$ \\
\hline & $6-10$ years & $19(20.9)$ & $3(3.3)$ \\
\hline & Above 11 years & $14(15.4)$ & $0(.0)$ \\
\hline & TOTAL & $91(100)$ & $91(100)$ \\
\hline
\end{tabular}

respondents was 37.2; SD 7.6 for the index subjects and 36.9; SD 7.6 for the comparative group. Majority of patients were single in the index group $54.9 \%$, while majority were married in the comparative group $63.7 \%$. In both the schizophrenia and HIV group, majority of patients were Christians $85.7 \%$ and $81.3 \%$ respectively. More of the schizophrenia patients had tertiary education $57.1 \%$ when compared to the HIV positive patients $35.2 \% .65 .9 \%$ of HIV positive respondents were employed as compared to $41.8 \%$ of schizophrenia patients. Majority of respondents in both groups had been aware of their diagnosis between 1-5 years; schizophrenia group $49.5 \%$, HIV positive group $82.4 \%$.

\section{Levels of stigma}

Table 2 shows the relationship between the sociodemographic parameters and the levels of the different components of self-stigma in schizophrenia patients. For patients in the schizophrenia group, those with a lower educational level (mean 8.49; SD 6.86) had a statistically higher level of self-stigma overall, than those with tertiary education (mean 5.31; SD 4.92, $\mathrm{p}=0.01$ ). This was similar for the alienation subscale (mean score for secondary education and below 2.69; SD 2.07, tertiary education, mean 1.87; SD 1.74, $\mathrm{p}=0.04$ ), and stereotype experience (mean score for secondary education and below 1.62; SD 1.68, tertiary education mean 0.88; SD 1.11, p=0.02). However, those with below secondary education had a statistically higher mean score on discrimination experience (mean, 2.08; SD 1.90), when compared to those with tertiary education mean, 1.13; SD 1.41 $(p=0.01)\}$. For the occupational status, the unemployed also had an overall higher mean score of self stigma (mean, 7.89; SD 5.61), when compared the employed, 
Table 2: Relationship between self-stigma and sociodemographics variables in schizophrenia group

\begin{tabular}{|c|c|c|c|c|c|c|}
\hline \multirow{3}{*}{ AGE } & \multicolumn{4}{|c|}{ SCHIZOPHRENIA } & & \\
\hline & \multicolumn{2}{|c|}{$<40$ yrs $(n=54)$} & \multicolumn{2}{|c|}{$>40$ years $(n=37)$} & & \\
\hline & M & SD & M & $\mathrm{SD}$ & $t$ & $p$-value \\
\hline Alienation & 2.09 & 1.80 & 2.41 & 2.09 & .76 & .45 \\
\hline Stereotype Experience & 1.04 & 1.36 & 1.43 & 1.50 & 1.31 & .20 \\
\hline Discrimination Experience & 1.41 & 1.72 & 1.73 & 1.66 & .89 & .38 \\
\hline Social Withdrawal & 1.28 & 1.45 & 1.05 & 1.39 & .74 & .46 \\
\hline Self-Stigma & 6.24 & 5.68 & 7.30 & 6.49 & .82 & .41 \\
\hline \multirow[t]{2}{*}{ GENDER } & \multicolumn{2}{|c|}{ Male $(n=48)$} & \multicolumn{2}{|c|}{ Female $(n=43)$} & & \\
\hline & M & SD & M & $\mathrm{SD}$ & $\mathrm{t}$ & P-value \\
\hline Alienation & 2.31 & 1.95 & 2.12 & 1.91 & .49 & .63 \\
\hline Stereotype Experience & 1.02 & 1.39 & 1.40 & 1.45 & 1.26 & .21 \\
\hline Discrimination Experience & 1.25 & 1.58 & 1.86 & 1.78 & 1.73 & .09 \\
\hline Social Withdrawal & 1.19 & 1.41 & 1.19 & 1.45 & .01 & .99 \\
\hline Self-Stigma & 6.21 & 5.83 & 7.19 & 6.23 & .77 & .44 \\
\hline \multirow[t]{2}{*}{ MARITAL STATUS } & \multicolumn{2}{|c|}{ N. Marr(n=62) } & \multicolumn{2}{|c|}{ Married $(n=29)$} & & \\
\hline & M & $\mathrm{SD}$ & M & $\mathrm{SD}$ & $\mathrm{T}$ & P-value \\
\hline Alienation & 2.37 & 1.88 & 1.90 & 2.01 & 1.10 & .27 \\
\hline Stereotype Experience & 1.11 & 1.32 & 1.38 & 1.63 & .83 & .41 \\
\hline Discrimination Experience & 1.44 & 1.55 & 1.76 & 1.98 & .85 & .40 \\
\hline Social Withdrawal & 1.34 & 1.41 & .86 & 1.41 & 1.50 & .14 \\
\hline Self-Stigma & 6.77 & 5.61 & 6.45 & 6.90 & .24 & .81 \\
\hline \multirow[t]{2}{*}{ EDUCATIONAL STATUS } & \multicolumn{2}{|c|}{$<20(n=39)$} & \multicolumn{2}{|c|}{$30(n=52)$} & & \\
\hline & M & SD & M & $\mathrm{SD}$ & $t$ & P-value \\
\hline Alienation & 2.69 & 2.07 & 1.87 & 1.74 & 2.07 & .04 \\
\hline Stereotype Experience & 1.62 & 1.68 & .88 & 1.11 & 2.49 & .02 \\
\hline Discrimination Experience & 2.08 & 1.90 & 1.13 & 1.41 & 2.72 & .01 \\
\hline Social Withdrawal & 1.23 & 1.49 & 1.15 & 1.38 & .25 & .80 \\
\hline Self-Stigma & 8.49 & 6.86 & 5.31 & 4.92 & 2.58 & .01 \\
\hline \multirow[t]{2}{*}{ EMPLOYMENT STATUS } & \multicolumn{2}{|c|}{ Employ(n=38) } & \multicolumn{2}{|c|}{ Unemployed(n=53) } & & \\
\hline & $\mathrm{M}$ & SD & M & $\mathrm{SD}$ & $\mathrm{T}$ & P-value \\
\hline Alienation & 1.76 & 1.84 & 2.55 & 1.93 & 1.95 & .05 \\
\hline Stereotype Experience & .84 & 1.39 & 1.45 & 1.41 & 2.05 & .04 \\
\hline Discrimination Experience & 1.18 & 1.67 & 1.79 & 1.68 & 1.71 & .09 \\
\hline Social Withdrawal & 1.00 & 1.51 & 1.32 & 1.35 & 1.06 & .29 \\
\hline Self-Stigma & 4.97 & 6.20 & 7.89 & 5.61 & 2.34 & .02 \\
\hline \multirow[t]{2}{*}{ DURATION } & \multicolumn{2}{|c|}{$<3$ years $(n=41)$} & \multicolumn{2}{|c|}{$>3$ years $(n=50)$} & & \\
\hline & $\mathrm{M}$ & SD & $\mathrm{M}$ & $\mathrm{SD}$ & $\mathrm{T}$ & P-value \\
\hline Alienation & 2.32 & 1.84 & 2.14 & 2.00 & .44 & .66 \\
\hline Stereotype Experience & 1.24 & 1.45 & 1.16 & 1.42 & .28 & .78 \\
\hline Discrimination Experience & 1.44 & 1.58 & 1.62 & 1.79 & .50 & .62 \\
\hline Social Withdrawal & 1.39 & 1.39 & 1.02 & 1.44 & 1.24 & .22 \\
\hline Self-Stigma & 6.90 & 5.82 & 6.48 & 6.21 & .33 & .74 \\
\hline
\end{tabular}

\{mean 4.97; SD $6.20(\mathrm{p}=0.02)\}$ and a significantly higher mean score of stereotype experience (mean, 1.45; SD 1.41) when compared to the employed patients [mean, 0.84; SD $1.39(\mathrm{p}=0.04)\}$.

Table 3 shows the relationship between the sociodemographic parameters and the different components of self-stigma in HIV patients. The results show that there is a higher mean score in overall self-stigma in those that are not married (mean, 6.45; SD 4.59, $\mathrm{p}=0.01$ ) when compared to the married group, mean, (3.21; SD 4.59; $\mathrm{p}=0.01$ ). Also the not married group had a statistically higher level of alienation (mean, 2.42; SD 1.85) than the married group (mean, 0.97; SD $1.42, p=0.01$ ) and discrimination experience (mean, 1.39; $\mathrm{SD} 1.37$ ) versus (mean, 0.60; $\mathrm{SD} 1.20, \mathrm{p}=0.01$ ) in the married group.

Table 4 shows the prevalence of self-stigma in both schizophrenia and HIV groups. The prevalence for moderate to severe stigma is higher in the schizophrenia group $(47.3 \%)$ when compared to the HIV/AIDS group (38.5\%). Whereas, the reverse is the case for no-stigma to mild levels of self-stigma; Schizophrenia group (52.7\%); HIV positive group (61.5\%). 


\begin{tabular}{|c|c|c|c|c|c|c|}
\hline \multirow{3}{*}{ AGE } & \multicolumn{4}{|c|}{ HIV } & \multirow[b]{3}{*}{$\mathrm{t}$} & \multirow[b]{3}{*}{$p$-value } \\
\hline & \multicolumn{2}{|c|}{$<40$ yrs(n=55) } & \multicolumn{2}{|c|}{$>40$ yrs $(n=36)$} & & \\
\hline & $M$ & $\mathrm{SD}$ & $M$ & SD & & \\
\hline Alienation & 1.53 & 1.70 & 1.44 & 1.81 & .22 & .83 \\
\hline Stereotype Experience & .62 & 1.21 & .81 & 1.49 & .66 & .51 \\
\hline Discrimination Experience & .89 & 1.20 & .89 & 1.49 & .01 & .99 \\
\hline Social Withdrawal & 1.31 & 1.30 & 1.31 & 1.58 & .01 & .99 \\
\hline Self-Stigma & 4.36 & 4.28 & 4.42 & 5.61 & .05 & .96 \\
\hline \multirow[t]{2}{*}{ GENDER } & \multicolumn{2}{|c|}{ Male $(n=48)$} & \multicolumn{2}{|c|}{ Female $(n=43)$} & $t$ & P-value \\
\hline & M & $\mathrm{SD}$ & $M$ & SD & $T$ & P-value \\
\hline Alienation & 1.77 & 1.82 & 1.19 & 1.59 & 1.62 & .11 \\
\hline Stereotype Experience & .71 & 1.43 & .67 & 1.21 & .12 & .90 \\
\hline Discrimination Experience & .98 & 1.45 & .79 & 1.15 & .68 & .50 \\
\hline Social Withdrawal & 1.48 & 1.49 & 1.12 & 1.31 & 1.23 & .22 \\
\hline Self-Stigma & 5.02 & 5.35 & 3.67 & 4.10 & 1.34 & .19 \\
\hline \multirow[t]{2}{*}{ MARITAL STATUS } & \multicolumn{2}{|c|}{ N. Marr(n=33) } & \multicolumn{2}{|c|}{ Married $(n=58)$} & & \\
\hline & M & $\mathrm{SD}$ & M & SD & $T$ & P-value \\
\hline Alienation & 2.42 & 1.85 & .97 & 1.42 & 4.20 & .01 \\
\hline Stereotype Experience & .97 & 1.38 & .53 & 1.27 & 1.52 & .13 \\
\hline Discrimination Experience & 1.39 & 1.37 & .60 & 1.20 & 2.87 & .01 \\
\hline Social Withdrawal & 1.64 & 1.25 & 1.12 & 1.48 & 1.69 & .09 \\
\hline Self-Stigma & 6.45 & 4.59 & 3.21 & 4.59 & 3.25 & .01 \\
\hline \multirow[t]{2}{*}{ EDUCATIONAL STATUS } & \multicolumn{2}{|c|}{$2^{0}(n=59)$} & \multicolumn{2}{|c|}{$3^{0} .(n=32)$} & & \\
\hline & M & $\mathrm{SD}$ & M & SD & $T$ & P-value \\
\hline Alienation & 1.51 & 1.87 & 1.47 & 1.48 & .10 & .92 \\
\hline Stereotype Experience & .76 & 1.33 & .56 & 1.32 & .69 & .49 \\
\hline Discrimination Experience & .90 & 1.34 & .87 & 1.29 & .08 & .94 \\
\hline Social Withdrawal & 1.36 & 1.46 & 1.22 & 1.34 & .44 & .66 \\
\hline \multirow{3}{*}{$\begin{array}{l}\text { Self-Stigma } \\
\text { EMPLOYMENT STATUS }\end{array}$} & 4.56 & 5.08 & 4.06 & 4.38 & .47 & .64 \\
\hline & \multicolumn{2}{|c|}{ Employ. $(n=60)$} & \multicolumn{2}{|c|}{ Unemployed.(n=31) } & 1.06 & .29 \\
\hline & M & SD & M & SD & $\mathrm{T}$ & P-value \\
\hline Alienation & 1.27 & 1.63 & 1.94 & 1.86 & 1.77 & .08 \\
\hline Stereotype Experience & .70 & 1.44 & .67 & 1.08 & .08 & .94 \\
\hline Discrimination Experience & .72 & 1.28 & 1.23 & 1.33 & 1.78 & .08 \\
\hline Social Withdrawal & 1.10 & 1.31 & 1.71 & 1.53 & 1.98 & .05 \\
\hline Self-Stigma & 3.77 & 4.83 & 5.58 & 4.66 & 1.72 & .09 \\
\hline \multirow[t]{2}{*}{ DURATION } & \multicolumn{2}{|c|}{$<3 y r s(n=51)$} & \multicolumn{2}{|c|}{$>3$ years $(n=40)$} & & \\
\hline & M & SD & M & $\mathrm{SD}$ & $\mathrm{T}$ & P-value \\
\hline Alienation & 1.65 & 1.74 & 1.30 & 1.73 & .94 & .35 \\
\hline Stereotype Experience & .63 & 1.18 & .78 & 1.49 & .53 & .60 \\
\hline Discrimination Experience & .96 & 1.34 & .80 & 1.29 & .58 & .57 \\
\hline Social Withdrawal & 1.45 & 1.45 & 1.13 & 1.36 & 1.09 & .28 \\
\hline Self-Stigma & 4.71 & 4.68 & 3.97 & 5.02 & .71 & .47 \\
\hline
\end{tabular}

Table 5 shows generally, the mean scores for self-stigma were higher in the schizophrenia group when compared to the HIV group. On the alienation sub scale, the mean score for schizophrenia group was 2.22; SD 1.92. Mean score for HIV group was 1.49; SD 1.73. This difference was statistically significant at $\mathrm{p}=0.01$.

On the stereotype experience sub scale, the mean score for the schizophrenia group was also higher 1.20; SD 1.43 when compared to the HIV group 0.69; SD 1.32. This was also statistically significant at $\mathrm{p}=0.01$

While the schizophrenia group had a mean score of 1.54 ;
SD 1.70 on the discriminatory experience sub scale, the HIV positive respondents had a mean score of 0.89 ; SD 1.31 on this scale. This was also statistically significant at $\mathrm{p}=0.01$.

The reverse was however the case on the social withdrawal sub-scale. The HIV positive respondents had a mean score of 1.31; SD1.41 and the schizophrenia patients having a mean score of 1.19 ; SD 1.42, this was not statistically significant.

On the whole, the schizophrenia patients had a higher total mean score of 6.67 ; SD 6.01 , when compared to the HIV positive group with a mean score of 4.38; SD 4.38. This was statistically significant at $\mathrm{P}=0.01$. 


\begin{tabular}{|c|c|c|c|c|c|}
\hline Table 4: Prevalence of self-stigma in the schizophrenia and hiv groups \\
\hline PREVALENCE & SCHIZOPHERNIA & HIV & TOTAL & X & \\
\hline & $\mathrm{N}(\%)$ & $\mathrm{N}(\%)$ & $\mathrm{N}(\%)$ & 1.44 & \\
\hline No Stigma - Mild (<mean) & $48(52.7)$ & $56(61.5)$ & $104(57.1)$ & & \\
\hline Moderate - Severe Sigma (>mean) & $43(47.3)$ & $35(38.5)$ & $78(42.9)$ & & \\
\hline TOTAL & $\mathbf{9 1 ( 1 0 0 )}$ & $\mathbf{9 1 ( 1 0 0 )}$ & $\mathbf{1 9 2 ( 1 0 0 )}$ & & \\
\hline
\end{tabular}

\begin{tabular}{|c|c|c|c|c|c|c|}
\hline \multicolumn{1}{|c|}{ Table 5: Mean scores of self-stigma in the schizophrenia and hiv groups } & \multicolumn{2}{|c|}{ HIV (n= 91) } & SD & T & p-value \\
\hline & SCHIZOPHRENIA (n=91) & SD & M & 1.73 & 2.67 & .01 \\
\hline Alienation & M & 1.92 & 1.49 & 1.32 & .248 & .01 \\
\hline $\begin{array}{c}\text { Stereotype Experience } \\
\text { Discrimination Experi- } \\
\text { ence }\end{array}$ & 1.22 & 1.43 & .69 & 1.31 & 2.89 & .01 \\
\hline Social Withdrawal & 1.20 & 1.70 & .89 & 1.41 & .58 & .57 \\
\hline Self-Stigma & 1.19 & 1.42 & 1.31 & 4.83 & 2.83 & .01 \\
\hline
\end{tabular}

\section{Discussion}

This study attempted to assess and compare self-stigma among schizophrenia and HIV positive out patients in 2 hospitals in Lagos; 2 debilitating and highly stigmatizing illnesses. To the best of the authors' knowledge, it is the first of its kind in our environment. Previous studies have researched on perceived self-stigma in mental illness generally, not on a homogenous group of mental illness like schizophrenia, and they were not comparative studies.

We observed that the socio demographic correlates of self-stigma in the schizophrenia and HIV differed. While having a lower level of education, and being unemployed was correlated with a higher level of stigma for the schizophrenia patients, this was different for the HIV group. Those that were never married had a higher level of stigma, when compared to those that were married. These dissimilarities in the correlates of self-stigma in both groups could be explained by the fact that; since sexual intercourse has been reported to be the predominant mode of transmission, accounting for $80 \%$ of infections, infected individuals may be discriminated by non-infected persons, due to their fears of contacting the disease. Also infected individuals may be pre-occupied with worries of spreading the infection thus becoming socially withdrawn. There is evidence to suggest that individuals, who experience high levels of internal stigma, are socially withdrawn either due to lack of support, or self- imposed isolation, which has led some of them to exclude themselves from sexual and loving relationships. ${ }^{13}$ Social withdrawal may in-turn promote internalized stigma because the individual is unable to have supportive experiences which may help boost their self- esteem and self- efficacy. On the other hand, patients living with mental illness, particularly schizophrenia, don't enjoy as much advocacy and public enlightenment as is enjoyed by people living with HIV/AID (PLWHA). As such they suffer more discrimination from others, like from potential employers, which may lead to internalized stigma in them. Moreover, dearth of advocacy programs for schizophrenia patients in this environment may put them at a disadvantage with regards to their employment rights. This above mentioned reason also explains why a lower level of education is associated with a higher level of self-stigma in the schizophrenia group and not the HIV group. Inadequate public enlightenment programs on schizophrenia may lead to self stigma, as the more education and information that one has, the easier it is to overcome internal stigma. ${ }^{13}$ In other words the more they are able to fight with their self stigma, the better their ability to forge ahead with life's challenges and improve on their socioeconomic accomplishments like getting better education.

Overall, though the difference in the prevalence of self-stigma was not statistically significant in both groups, moderate to severe self-stigma was more prevalent in the schizophrenia than HIV positive group. There have been varying results on the prevalence of self- sigma in schizophrenia and HIV positive patients. Our finding of a prevalence of $47.3 \%$ of "moderate to severe stigma" in schizophrenia patients in this study, is close to the findings of 18 in their study carried out in Europe showed that 69.4 $\%$ of mentally ill patients reported moderate to high levels of perceived stigma. And the degree to which this belief was held was significantly associated with an increase in reported self -stigma. It was however concluded that overt expressions of stigma in PLWHA's has declined, and that only $33.3 \%$ of respondents expressed discomfort and negative feelings among PLWHA ${ }^{25}$.

The schizophrenia patients had higher mean scores of overall self- stigma, and also all the ISMI subscales (apart from, the social withdrawal subscale) when compared to the HIV group. This may not be surprising, in our environment, where there are many support and advocacy groups (both local and international) for PLWHAs. These groups are involved in pressing for legislations to be put in place, which will prohibit discrimination against PLWHA, in such key areas as employment and housing; in fact some of them go as far as seeking for meaningful involvement of HIV positive individuals in national decision making about HIV/ AIDS-related issues ${ }^{26}$. This is however not the case for the schizophrenia group. There are very few support groups for the mentally ill which are even yet to be recognized locally. Sadly, the latest mental health legislation in Nigeria was enacted in $1958 .{ }^{27} \mathrm{~A}$ revised mental health bill of 2003 , which is already getting obsolete, is now before the National assembly, yet to see the light of day ${ }^{28}$.

\section{Limitations of the Study}

The Study had some limitations. The sample size was moderate and recruitment of respondents was through 
convenient sampling method. Although the schizophrenia patients were recruited based on clinical diagnosis, a diagnostic instrument was not used for their recruitment.

\section{Conclusion}

The study demonstrates that self-stigma is a phenomenon present in both schizophrenia and people living with HIV. It is however much more severe in people living with schizophrenia. Urgent attention thus needs to be given to this group of individuals, by creating more support and advocacy groups in the country to reduce the level of stigma in them, thus improving their overall quality of life.

\section{References}

1. Brown L, Trujillo L, MacIntyre K. Interventions to reduce HIV/AIDS stigma: What have we learned? Horizons Program, Tulane University, September 2001; 15.

2. Yebei VN, Fortenberry JD, Ayuku DO. Felt stigma among people living with HIV/AIDS in rural and urban Kenya. African Health Sciences. 2008; 8: 97-102.

3. Busko M. Real and Perceived stigma in Schizophrenia severe, widespread. Medscape medical news 2009.

4. Thompson M, Thompson T. Discrimination Against people with experiences of Mental Illness. Wellington mental health Commission. 1997.

5. Bryne P. Stigma of mental illness and ways of diminishing it. Advances in Psychiatric treatment, 2000; 6: 65-72.

6. Watson AC, Corrigan PW, Larson JE, Sells M. Self-stigma in people with mental illness. Schizophrenia Bulletin, 2007; 33: $1312-1318$.

7. Corrigan PW, Kleinlein P. The impact of mental illness stigma In P.W. Corrigan (ed), On the stigma of mental illness. Washington, DC: American Psychological Association, 2005; 11-44.

8. Link BG. Understanding labeling effects in the area of mental disorders: An assessment of the effects expectations of rejection. American Sociological Review. 1987; 52: 96-112.

9. Lee $S$, Chiu MYL, Tsang A. Stigmatizing experience and structural discrimination associated with the treatment of schizophrenia in Hong Kong. Social Science \& medicine. 2006; 1685-1696.

10. Dickerson FB, Sommerville J, Origoni AE. Experiences of stigma among out patients with schizophrenia. Schizophrenia Bulletin, 2002; 28:143-155.

11. Fink PJ, Tasman A. Stigma and Mental illness. Washington, DC:American Psychiatric Press. Kommana S, Mansfield M, and Penn DL (1997). Dispelling the stigma of schizophrenia. Psychiatric services, 48:1393-1395, 1997. Sartorius, N. (1998). Stigma: what can psychiatrists do about it? The Lancet (352) 9133: 1054-1055. Bryne P. Stigma of mental illness: changing minds, changing behavior. British Journal of Psychiatry 1999; 174: 1- 2.

12. Mayville E, Penn DL. Changing societal attitudes towards people with severe mental illness. Cognitive and behavioural Practice 1998; 5: 241-253. Corrigan PW, Penn DL. (1999). Lessons from social psychology on discrediting psychiatric stigma. American Psychologist, 54, 765 - 776
13. Parker R, Aggleton P (UNAIDS). HIV and AIDS-related stigma and discrimination: a conceptual framework and implications for actions. Sosial Science and Medicine, 2000; 57: 13-24.

14. Bollinger L. "Literature Review of General and HIV-related Stigma." Washington, DC: POLICY Project/Futures Group, 2002.

15. Brakel WH. Measuring health-related stigma- a Literature review. vs2, 14 September, 2005.

16. Lau JTF, Tsui HY. Comparing the magnitude of discriminatory attitudes toward people living with HIV/ AIDS and toward people with mental illness in Hong Kong general hospital. Health education research, 2006; 1: 139152.

17. Brohan E, Elgie R, Sartorius N. Self-stigma, empowerment and perceived discrimination among people with schizophrenia in 14 European countries: The GAMIANEurope study, 2010.

18. Sorsdahl. The internalized stigma experienced members of a mental health advocacy group in South Africa. International journal for social psychiatry, 2010.

19. Ghanean H, Nojomi M, Jacobsson L. Internalized Stigma of mental illness in Tehran, Iran. Stigma research and action, 2011;1:11-17.

20. Adewuya AO, Owoeye AO, Erinfolami AO. Correlates of self-stigma among out-patients with mental illness in Lagos Nigeria. International Journal of social psychiatry. March 302010.

21. Fabrega H. (1991). Psychiatric stigma in non-Western countries. Comprehensive Psychiatry, 32, 534-551. Gureje O, Lasebikan VO, Ephraim-Oluwanuga O. (2005). Community Study of knowledge of and attitude to mental illness in Nigeria. The British journal of Psychiatry (2005); 186: 436-441.

22. Ritsher JB, Otilingam PG, Grajales M. Internalized stigma of mental illness: Psychometric properties of a new measure. Psychological research, 2003; 121: 31-49.

23. Adewuya AO, Makanjuola ROA. Social distance towards people with Mental illness in South Western Nigeria. Australian and New Zealand Journal of Psychiatry, 2008; 42: 389-395.

24. Askew IP, Berer M. The contribution of sexual and reproductive health services to fight against HIV/AIDS, $A$ review of Reproductive Health Matters II (22) 2013; 51 - 73.

25. United States Agency for International Development (USAID). Can we measure HIV/AIDS-related stigma and discrimination? Current knowledge about quantifying stigma in developing countries. January 2006.

26. Herek GM. Thinking about AIDS and Stigma: $A$ psychologist's perspective. The Journal of Law, Medicine \& Ethics. 2002; 30: 594-607.

27. Fhi360 the science of improving lives (2012).

28. WHO. Mental health Atlas. 2005.

29. Olu F.The nation newspaper. The world of mental health in Abuja, published 24th of October 2009. 